\title{
Por entre as linhas dos dispositivos: desafios das práticas contemporâneas na interface terapia ocupacional e cultura ${ }^{1}$
}

\author{
Isabela Umbuzeiro Valent, Eliane Dias de Castro
}

Departamento de Terapia Ocupacional, Universidade de São Paulo - USP, São Paulo, SP, Brasil.

\begin{abstract}
Resumo: Este artigo tece reflexões sobre os desafios de instauração de práticas na interface da terapia ocupacional e da cultura, e toma como referência estudos de um campo problemático, definido pela biopolítica enquanto regime de poder hegemônico, que compõe os domínios dessas áreas de atuação. Aponta, assim, questões para a construção de estratégias de participação social e cultural de pessoas que, por múltiplas razões, vivem situações de vulnerabilidades. Essas populações, tradicionalmente atendidas no campo da terapia ocupacional, vivem de forma singular a circulação nos diferentes espaços da cidade e desafiam a criação de ações inovadoras e transversais, que afirmem encontros e projetos de vida coletiva. As práticas artísticas engendradas numa determinada perspectiva crítica destacam-se enquanto alternativas para ativar experimentações que possibilitam a produção de subjetividades a partir da heterogênese. São contribuições ao conjunto de estudos interdisciplinares que dão sustentação às ações complexas e intersetoriais, que operam a produção da autonomia e a efetuação das políticas culturais.
\end{abstract}

Palavras-chave: Terapia Ocupacional, Tendências, Cultura, Vulnerabilidade Social, Subjetividade, Arte.

\section{Between the devices lines: challenges of contemporary practices in occupational therapy and culture interface}

\begin{abstract}
This work discusses the challenge of establishing practices on the interface of occupational therapy and culture. It is based on studies on the problematic field defined by biopolitcs as a regime of hegemonic power composed by the domains of both these areas. It points out topics for the construction of social and cultural participation strategies for people who, for several reasons, live in vulnerable situations. These populations, traditionally received in the field of occupational therapy, circulate differently in the city and challenge the creation of innovative and transversal actions that affirm collective encounters and projects. The artistic practices engendered in certain critical perspective, appear as alternatives to activate experiments that make possible the production of subjectivities from heterogenesis. They are contributions to the set of interdisciplinary studies supporting complex and intersectorial actions which produce autonomy and cultural policies.
\end{abstract}

Keywords: Occupational Therapy, Trends, Culture, Social Vulnerability, Subjectivity, Art.

Autor para correspondência: Isabela Umbuzeiro Valent, Departamento de Terapia Ocupacional, Universidade de São Paulo, Rua Cipotânea, 51 , Butantã, CEP 05360-160, São Paulo, SP, Brasil, e-mail: isabelavalent@usp.br 


\section{Introdução}

Todos e qualquer um inventam, na densidade social da cidade, na conversa, nos costumes, no lazer - novos desejos e novas crenças, novas associaçôes e novas formas de cooperação. A invenção não é prerrogativa dos grandes gênios, nem monopólio da indústria ou da ciência, ela é a potência do homem comum. Cada variação, por minúscula que seja, ao propagar-se e ser imitada torna-se quantidade social, e assim pode ensejar outras invenções e novas imitações, novas associações e novas formas de cooperação. Nessa economia afetiva, a subjetividade não é efeito ou superestrutura etérea, mas força viva, quantidade social, potência psíquica e política (PÈLBART, 2008, p. 38).

Diante da ampliação da participação de terapeutas ocupacionais em dispositivos desenvolvidos na interface entre as práticas sociais, de saúde e de cultura, torna-se cada vez mais importante tecer reflexôes que discutam problemáticas relativas às estratégias de participação social e cultural de pessoas que, por múltiplas questôes, vivem situaçóes de vulnerabilidades. Apresentamos, neste artigo, parte dos resultados da pesquisa de mestrado que buscou acolher experiências concretas com essas populaçôes e integra a crescente produção de métodos e conhecimentos interdisciplinares na interface da terapia ocupacional e da cultura. Sáo experiências que apontam questóes ligadas à participação sociocultural de populaçóes tradicionalmente acompanhadas pela terapia ocupacional, em diferentes contextos de atuação. Essas populaçôes, por diversas problemáticas, vivem processos que restringem sua participação na vida social, simbólica e cidadã. Para acolher e encontrar estratégias às suas complexas demandas, são necessárias práticas transversais e a configuração de campos interdisciplinares de conhecimento.

As experiências vividas no cotidiano dessas práticas apontam elementos de mobilizaçóes na malha cultural e permitem uma imersão cotidiana num conjunto de fazeres: relacionais, de ampliação das possibilidades comunicacionais, de cuidado e de emancipação cultural, ressaltando a necessidade de invenção de açôes que tocam domínios distintos do conhecimento e que se inserem em diferentes políticas públicas.

Na pesquisa, foram acompanhados três projetos caracterizados por experimentaçóes fotográficas e audiovisuais em dispositivos, nos quais participam pessoas com marcas de vulnerabilidades ligadas a questôes relacionadas a saúde mental, rupturas sociais e deficiências. Além disso, os projetos propóem a circulação na cidade, a realização de produçóes artísticas colaborativas e a convivência. Nesse processo, buscou-se articular as experiências acompanhadas com conceitos de diferentes campos de conhecimento: filosofia, artes, terapia ocupacional e políticas culturais, produzindo, a partir do método da cartografia, reflexôes transdisciplinares (VALENT, 2014).

O método cartográfico, inspirado pela Filosofia da Diferença de Deleuze e Guattari, se alia à discussão mais geral da crítica aos especialismos e aposta na transdisciplinaridade, enquanto desestabilizaçáo do que se delimita como campo de uma disciplina. Atravessando diferentes domínios, provocando interlocuções, aceitando os desafios de se pensar no limite entre os saberes, a transdisciplinaridade coloca em questáo os objetos bem definidos e as teorias internamente consistentes, a preexistência de sujeitos do conhecimento e objetos a serem conhecidos, os campos bem demarcados das práticas discursivas e não discursivas, os especialistas defensores de territórios identitários de conhecimento. Com a desestabilizaçáo, emerge o plano de constituição de domínios de conhecimento em que as dicotomias dão lugar aos híbridos e as fronteiras apresentam seus graus de abertura, suas franjas móveis, por onde os saberes se arguem e as práticas mostram sua complexidade (PASSOS; KASTRUP; ESCÓSSIA, 2010).

Os acompanhamentos instauraram passagens fecundas que tensionam a proposição de práticas e suas reflexóes, desdobrando-se num embaralhamento e contaminação entre os diferentes campos de conhecimento e atuação aqui desenvolvidos: das artes, da produção da saúde e da cultura. A partir dessas cartografias, produziram-se problematizaçóes que contribuem para delinear analisadores de situaçóes de sofrimento e exclusão, nos processos de subjetivação contemporâneos. O estudo apontou a configuração de um campo problemático definido pela biopolítica enquanto regime de poder hegemônico, que compóe os domínios da terapia ocupacional e da cultura num contexto onde a prevalência da discursividade sobre as vivências prescreve nosso modo de relação com as práticas, blindando assim possibilidades de se adensarem e diversificarem as experiências.

As práticas fotográficas e audiovisuais, nesses projetos, ofereceram a possibilidade de experimentar outros processos de relação com a imagem e de circulação pelo território, destacando aspectos singulares dessas atividades: estas acontecem em diferentes espaços da cidade e da vida coletiva. As atividades têm, como ponto de partida, o serviço de saúde mental, o centro de convivência, o ateliê, o consultório, passam pelas ruas, casas dos participantes, centros 
culturais, ônibus, trens, metrôs, bicicletas, cafés, lojas, bancas de jornal, aeroportos, museus, praças etc. Mas se dão, sobretudo, nos percursos entre diferentes espaços e no movimento dessas pessoas que coletivamente circulam e, assim, produzem experiências na cidade.

A prerrogativa dos encontros era a de produzir imagens: oficina de vídeo documentário, oficina de fotografia, oficina de formação cultural, mas se percebia que, em cada participante, existiam também outras expectativas e desejos que os mobilizavam: conviver, se tratar, passear, pertencer etc. As passagens a seguir exprimem paisagens desses três projetos:

Nos primeiros dias das oficinas do NAVE os encontros pareciam sem graça, a conversa não dava conta do embaraço do contato, os diferentes modos subjetivos de cada um pareciam chocar-se, um pouco atrapalhados. Câmera na mão. Ação. Olhares se revelam nas filmagens silenciosas de uns, outros descobrem curiosidades e se interessam pelo outro, habilidades tornam-se visiveis, histórias e risadas passam a circular nos encontros. O grupo sai às ruas, descobrem-se novas possibilidades de apresentação além de "pacientes", "doentes" $e$ "terapeutas", passam a fazer parte do repertório outras denominaçôes como estudantes, produtores de filme, repórteres ${ }^{2}$.

Durante muito tempo a fotografia era realizada com o intuito de registrar a circulação que o Encontrar-te fazia pela cidade, mas quando se passou a usar a fotografia como proposta de produção criativa aconteceu uma inversão: as escolhas dos lugares por onde circular passaram a surgir a partir do desejo de fotografar objetos, cenas e pessoas. O gesto de fotografar conduziu, aos poucos, descobertas de desejos, encontros e concretizaçôes que em muito devem à potência grupal e de criação para acontecerem ${ }^{3}$.

Caminhamos em bando, alguns carregando retratos em preto e branco impressos em folhas do nosso tamanho, outros equipados com câmeras fotográficas e filmadoras. Durante o percurso, cruzamos diversos personagens. Alguns nos acompanham, outros brincam e dialogam. Estamos a caminho da Câmara dos Vereadores. Lá colamos os 34 retratos de pessoas comuns, de nós mesmos, participantes do Ponto de Cultura É de Lei. "Esse ai está sendo procurado?", "É um candidato?", "Nâo acredito que é você" são as falas que nos rodeiam. Alguns daqueles nos retratos moram ali perto, dormem sob o céu na praça da Sé. Muitas vezes despercebidos pelos transeuntes, naquele momento davam uma entrevista sobre o projeto para o jornal localt.
Assim, ao captar ou produzir imagens, nota-se que muitas experiências se produzem em diferentes processos: criativos, clínicos, estéticos, políticos e éticos. Esses fazeres abrem possibilidades para outras circulaçôes de imagens, engendram acontecimentos nos espaços sociais e instauram contextos de convivência a partir da diversidade cultural.

Os temas selecionados a seguir são linhas analisadoras da complexidade das experiências e da intervenção na interface terapia ocupacional e cultura. São estas que adensam a problematização das açóes e reflexóes deste campo, que atualmente se constitui com a contribuição efetiva de terapeutas ocupacionais.

\section{Terapia Ocupacional em Tempos de Biopolítica}

Segundo Elizabeth Lima (2003), podemos localizar a terapia ocupacional num campo de práticas e saberes que se estabelece historicamente, para responder a problemáticas relacionadas a populaçóes que, por razóes diversas, sofreram a açáo de processos de exclusão. Sob esta perspectiva, esta profissão nasce sob o domínio de açóes disciplinares que visam a docilizar os corpos com o intuito de inseri-los no sistema de produçáo e circulação de mercadorias. Mas, para a autora, algumas formas contemporâneas de se fazer terapia ocupacional têm invertido essa lógica disciplinar, "[...] afirmando o direito à diferença e encontrando positividade em formas de vida, as mais singulares, e em situações, as mais adversas" (LIMA, 2003, p. 65).

A Terapia Ocupacional - sua função originária entre as profissões da área da saúde, seu desenvolvimento e sua vinculação às políticas sociais - está circunscrita à biopolítica, já que, nos diversos contextos de atuação, o terapeuta ocupacional é convocado a tratar diferentes sujeitos e grupos que trazem rubricas atreladas à sua posição no coletivo: pessoas com deficiências físicas ou intelectuais, pessoas com sofrimentos psíquicos, portadoras de transtornos e síndromes, dependentes químicos, pessoas em situação de vulnerabilidade, idosos, populaçôes carcerárias, jovem em conflito com a lei etc. Diagnósticos náo cessam de se multiplicar para explicar situaçóes que desviam e escapam aos modelos normativos vigentes.

O termo biopolitica, proposto por Michel Foucault (1997), se refere às transformaçôes dos mecanismos de poder entre o fim do século XVIII e o início do século XIX, em que a vida passa a fazer parte de seus domínios. Numa estreita relação com o liberalismo, os poderes passam a operar a partir do governo sobre a vida. Essa tecnologia tem como objeto a populaçáo e sua gestão, regulando e controlando 
comportamentos, definindo populaçóes específicas a partir de categorizaçóes. Neste mecanismo de controle, o poder torna-se capilar e opera numa individualização que pretende modelar cada indivíduo, gerindo sua vida.

Dentre distintas atribuiçóes dos profissionais de saúde, comumente compete a um terapeuta ocupacional propiciar processos de inclusão social para essas populaçóes. Diante do perigo de que essa tarefa atribuída à terapia ocupacional se constitua enquanto biopoder, Erika Inforsato (2011, p. 930) atenta para os riscos que a posição dessas práticas pode gerar:

Bem intencionados, oferecemos à humanidade critérios para uma adaptação inclusiva, e com isto, retiramos dela a força, a debilitamos e, nela, instituímos os sentimentos de horror e apiedamento diante da inadequação - corroborando para uma cultura de intolerância, apaziguamento e exclusão.

A autora provoca-nos a pensar os modos de fazer terapia ocupacional e suas funçôes no conjunto das açôes de cuidado vinculadas a essas populaçôes. Ela afirma que

[...] não deve ser a caridade a nos mover, não deve ser o ímpeto de correção a nos justificar. Nossa alma precisa poder colocar-se ao lado de outra alma. É por simpatia, e não por adaptação, que o desejo pela vida nos coloca em encontros (INFORSATO, 2011, p. 934).

Nas práticas desenvolvidas em terapia ocupacional, é muito comum observar que aqueles diagnosticados com alguma condição de doença, deficiência ou vulnerabilidade tenham seus espaços de circulação e pertencimento restritos aos serviços de tratamento, reabilitação ou de assistência social, como quase únicos espaços de circulação e pertencimento. Esse processo de estigmatizaçáo evidencia aspectos de uma lógica identitária de pertencimento que nos atravessa a todos, como aponta Elizabeth Lima (2003, p. 66):

O efeito de normalização atravessa toda a população, instaurando a tendência a categorizar e classificar cada uma das pequenas fragilidades que venham em algum momento tomar corpo e se fazer presente na vida cotidiana, de forma a se construir uma certa gradação entre normal e anormal.

Para Foucault (1995), os biopoderes não operam a partir de instituiçôes específicas, mas se compóem por dispositivos, ou seja, técnicas, estratégias e modos de assujeitamento usadas pelo poder. O dispositivo é
[...] um conjunto decididamente heterogêneo que engloba discursos, instituiçôes, organizaçóes arquitetônicas, decisóes regulamentares, leis, medidas administrativas, enunciados científicos, proposiçôes filosóficas, morais, filantrópicas. Em suma, o dito e o não dito são os elementos do dispositivo. O dispositivo é a rede que se pode estabelecer entre esses elementos [...] um tipo de jogo, ou seja, mudanças de posição, modificações de funçôes, que também podem ser muito diferentes (FOUCAULT, 1995, p. 77).

$\mathrm{Na}$ terapia ocupacional atual, acompanha-se a ampliação dos campos de intervenção e pesquisa, e uma tendência de que as práticas de desloquem do âmbito das instituiçôes de saúde ou de reabilitação para o encontro à vida, que se faz no território das cidades. Tais práticas passam a se dar também no campo social, na educação e na cultura, em dispositivos transversais e socioculturais, nos lugares onde a vida cotidiana se desenvolve (CASTRO; SILVA, 2007).

São estratégias para responder a demandas complexas das populaçóes atendidas, afetadas de forma intensa pelas questôes sociopolíticas que nos atravessam, garantindo a elas "[...] participação em espaços socioculturais da coletividade urbana” (LIMA et al., 2009, p. 146). Entende-se, assim, que as propostas contemporâneas, que tocam contextos socioculturais, contribuem para a produção da saúde, para a participação na vida coletiva e para a construção da autonomia e da emancipação, justamente porque têm a potência de promover aberturas, enriquecer cotidianos, redefinir papéis sociais e inventar outros lugares sociais.

\section{Culturas em Tempos de Biopolítica}

Da mesma maneira que o burguês Molière descobre que ele "faz prosa", as sociedades primitivas descobrem que "fazem cultura"; elas são informadas, por exemplo, de que fazem música, dança, atividades de culto, de mitologia, etc. E descobrem isso sobretudo no momento em que pessoas vêm lhes tomar a produção para expô-la em museus ou vendê-las no mercado de arte ou para inseri-la nas teorias antropológicas científicas em circulação. Mas elas não fazem nem cultura, nem dança, nem música. Todas essas dimensôes são inteiramente articuladas umas às outras num processo de expressão, e também articuladas com sua maneira de produzir bens, com sua maneira de produzir relações sociais. 
Ou seja, elas não assumem, absolutamente, essas diferentes categorizaçóes que são as da antropologia. A situação é idêntica no caso da produção de um indivíduo que perdeu suas coordenadas no sistema psiquiátrico, ou no das crianças antes de sua integração ao sistema de escolarização. Elas brincam, articulam relaçóes sociais, sonham, produzem e, mais cedo ou mais tarde, vão ter que aprender a categorizar essas dimensões de semiotização no campo social moralizado. Agora é hora de brincar, agora é hora de produzir para a escola, agora é hora de sonhar, e assim por diante (ROLNIK; GUATTARI, 1989, p. 29).

Os mesmos mecanismos de poder operam em outros campos, que também passam a incumbir-se da tarefa de inclusão social de pessoas situadas à margem. A cultura também é convocada à incumbência dessa inclusão, passando a ser abordada, em certas políticas, como ferramenta para o desenvolvimento de populaçóes minoritárias e de exercício da cidadania.

Acerca desse assunto, Stuart Hall (1997) aponta questóes que remetem a uma centralidade da cultura no contemporâneo, a qual ele denomina virada cultural. Segundo o autor,

A “virada cultural” está intimamente ligada a esta nova atitude em relação à linguagem, pois a cultura náo é nada mais do que a soma de diferentes sistemas de classificação e diferentes formaçóes discursivas aos quais a língua recorre a fim de dar significado às coisas. O próprio termo "discurso" refere-se a uma série de afirmaçôes, em qualquer domínio, que fornece uma linguagem para se poder falar sobre um assunto e uma forma de produzir um tipo particular de conhecimento. $\mathrm{O}$ termo refere-se tanto à produção de conhecimento através da linguagem e da representaçáo, quanto ao modo como o conhecimento é institucionalizado, modelando práticas sociais e pondo novas práticas em funcionamento (HALL, 1997, p. 25, grifo nosso).

O autor evidencia o caráter de regulação que a cultura exerce nas nossas práticas sociais, constituída por arranjos de poder discursivos e simbólicos, que se operam através de normatizaçóes dos comportamentos e das formas de agir no cotidiano. Esse caráter normativo define formas e propósitos dos nossos hábitos, tornando nossas açóes inteligíveis - previsíveis, regulares, ordenadas - aos outros, inscrevendo cada um de nossos gestos numa cultura comum a todos. Todos esses elementos contribuem para definir quem está dentro e quem está " fora dos limites normativos e discursivos de nosso modo particular de fazer as coisas". Assim, sistemas classificatórios delimitam cada cultura, comparando práticas humanas e delimitando condutas distintas em relação à pessoas cujos hábitos escapam à norma instituída. Outra forma de controle através da cultura é aquela que leva os sujeitos a regularem-se a si mesmos. Estratégias de mudanças de cultura organizacionais, como, por exemplo, na construçáo de sujeitos empreendedores, trabalham de modo a influir diretamente na subjetividade dos envolvidos.

A estratégia é alinhar as motivaçóes e aspiraçóes pessoais e subjetivas de cada sujeito às motivações da organização, redefinir suas habilidades e capacidades conforme as especificaçóes pessoais da empresa, internalizar objetivos organizacionais como suas próprias metas (HALL, 1997, p. 34).

Diante desses mecanismos de poder, torna-se vital refletir também sobre o papel de regulação que a cultura exerce. Para o autor,

Toda a nossa conduta e todas as nossas açóes são moldadas, influenciadas e, desta forma, reguladas normativamente pelos significados culturais. Uma vez que a cultura regula as práticas e condutas sociais, neste sentido, então, é profundamente importante quem regula a cultura. A regulação da cultura e a regulação através da cultura são, desta forma, íntima e profundamente interligadas (HALL, 1997, p. 34)

Neste contexto, políticas culturais vêm sendo empregadas em nome da inclusão e da participação sociocultural de grupos à margem. Porém, ao mesmo tempo em que permitem o acesso à cultura e a validação da produção simbólica desses sujeitos, essas políticas culturais correm o risco de se fazerem, também, a partir de uma lógica de controle.

Nomear, categorizar, classificar, distribuir os indivíduos em grupos de pertença, divididos por semelhanças como as de raça, as de gênero, as de faixa etária, as de classe é congelar os processos de produção da subjetividade em identidades estáticas, fechando a pluralidade em guetos, impedindo a possibilidade de diferenciação. [...] Os vários etnocentrismos têm se mantido em função de práticas que classificam modos de existir de primitivos, não civilizados, carentes, não desenvolvidos diante das práticas de grupos específicos que se agenciam para controlar a produção e reprodução dos bens culturais (LEMOS, 2007, p. 63). 
É crescente, nas políticas culturais atuais, a valorização e o fomento de produçôes para além das linguagens artísticas enquanto formas de expressão, tradicionalmente incluídas no sistema da cultura numa lógica que segue o sistema da arte. Como exemplo dessas iniciativas, está o Programa Cultura Viva - Cultura, Educaçáo e Cidadania, que foi criado em 2004, pela extinta Secretaria de Programas e Projetos Culturais do MinC, durante a gestão do Ministro Gilberto Gil. Constitui-se como uma política pública de cultura que visa a garantir o acesso dos cidadáos aos direitos culturais. A perspectiva compreende a produção de cultura como um processo e não como um produto. Efetivamente funciona através de convênio firmado entre governo e organizaçóes da sociedade civil que produzem cultura, criando assim uma rede de pontos de cultura. $\mathrm{O}$ programa inclui o financiamento público das atividades do ponto de cultura com gestão compartilhada (LIMA, 2013; TURINO, 2010).

Com essa implantação, iniciou-se a construçáo de um plano coletivo, no qual, de fato, colocam-se em operação as políticas públicas de cultura, revigorando a cultura em sua dimensão pública e de produção coletiva. Essa implantação vem instaurando um compromisso de muitos atores envolvidos, num interjogo entre macropolítica e micropolíticas, e colocam em fluxo um movimento constante de

[...] conformação de propósitos, intervençôes, sentidos, enfim, de políticas públicas orientadas para a criação de valor como expressão do poder constituinte dos processos sociais (GUIZARDI; CAVALCANTI, 2009, p. 113).

Ao valorizar a produção cultural e artística de comunidades não inseridas no sistema da arte, o que se percebe é que, muitas vezes, essas políticas culturais se dirigem a grupos específicos, definidos por categorias que parecem ser mais ligadas a definiçôes sociológicas do que à afirmaçáo dos direitos culturais de qualquer sujeito. Essa forma de incluir as comunidades pode evidenciar uma distinção desigual dessas produções e daquelas inseridas nas políticas culturais pela produção artística, já validada nesse sistema. Aqui, o cuidado necessário é evitar que, ao instituir vias exclusivas de acesso a determinados grupos sociais, não se acentuem marcas que acabem por reiterar processos de estigmatização e sufoquem os processos de invenção que a dimensão comum da vida humana faz emergir.

\section{Cultura é a Regra, Arte é a Exceção}

Em Je Vous Salue Sarajevo (1993), uma breve montagem cinematográfica de Jean-Luc Godard ${ }^{6}$, imagens fotográficas - que, posteriormente, descobre-se que são recortes de uma única fotografia de uma situação de guerra - apresentam-se na tela enquanto uma voz, em off, diz:

\section{De certa forma, o medo é o filho de Deus, redimido na noite de sexta-feira. Ele não é belo, é zombado, amaldiçoado e renegado por todos. Mas não entenda mal, ele cuida de toda agonia mortal, ele intercede pela humanidade. Pois há uma regra e uma exceçáo. Cultura é a regra. E arte a exceção. Todos falam a regra: cigarro, computador, camisetas, TV, turismo, guerra. Ninguém fala a exceçáo. Ela náo é dita, é escrita: Flaubert, Dostoyevski. É composta: Gershwin, Mozart. Épintada: Cézanne, Vermeer. É filmada: Antonioni, Vigo. Ou é vivida, e se torna a arte de viver: Srebenica, Mostar, Sarajevo. A regra quer a morte da exceção. Entáo a regra para a Europa Cultural é organizar a morte da arte de viver, que ainda floresce. Quando for hora de fechar o livro, eu não terei arrependimentos. Eu vi tantos viverem tão mal, e tantos morrerem tão bem?}

"Todos falam a regra. Ninguém fala a exceção". Como se manifesta aquilo que escapa ao aprisionamento de um discurso? Onde persiste aquilo que desvia, que desestabiliza os dispositivos de poder? A dimensão da arte, aqui em questão, não se trata de sua concepção enquanto prática social denominada pela cultura, ou seja, o dispositivo da arte - suas instituiçóes, seus discursos, seus mercados etc. Estes estáo também submetidos aos mesmos mecanismos de poder, fazem parte desse dispositivo. A essa concepção de arte proposta por Godard, podemos aproximar a noção de experiência estética, marcando uma diferença em relação à noção de experiência artística. Tomam-se, como artísticas, aquelas localizadas no campo definido como domínio da arte. Já as estéticas referem-se a um domínio de atividades e experiências que ultrapassam os limites do campo da arte, remetendo a acontecimentos que operam transformaçóes qualitativas na forma das coisas e nos modos de perceber o mundo, para além da discursividade em que essas se inserem.

A atividade estética pode estender-se para domínios bastante vastos da produção humana, artísticos e não artísticos, podendo sobreviver sem o recurso da ideia de obra (FAVARETTO, 1985, p. 97).

Na arte contemporânea, busca-se constantemente atravessar os limites colocados pelo sistema da arte, em tentativas de escapar da captura discursiva que tudo classifica, criando rupturas. 
Chama-se "arte contemporânea", há muito tempo - e talvez infelizmente, pois essa definição não é sociológica -, o ato de transgressão da fronteira, que tende sempre a se reinstaurar, entre o que é admissível no campo da arte e o que não é, ou não o é ainda. Ultrapassar esse limite a fim de torná-lo perceptível e consciente, eis o que é próprio de uma arte que, com ou sem razáo, confiscou a denominação de "arte contemporânea" (GALARD, 2012, p. 61).

Mas, no contexto contemporâneo, a instituição da arte não pode mais ser definida em termos espaciais, como as galerias e os museus, pois esta envolve uma rede discursiva de diferentes práticas e instituiçôes, outras subjetividades e comunidades, deslocando-se para o campo ampliado da cultura, espaço também pensado pela antropologia (FOSTER, 1996). Manifestaçôes estéticas dentro e fora do sistema da arte, em relação com este, surgem. Artistas - sob a legitimaçáo do sistema da arte - saem de seus domínios adentrando experiências no cotidiano da cidade. Habitam zonas em que se embaralham em açôes ativistas, etnográficas, pedagógicas, assistenciais, terapêuticas, políticas, éticas etc. No ensaio $O$ artista enquanto etnógrafo, Hal Foster (1996) aponta os perigos do que ele denomina patronato ideológico em práticas da arte contemporânea, que se constroem a partir do contato do artista com outro definido em termos antropológicos, culturais ou étnicos. Essa ideia remete ao risco de que se mantenha uma cisão entre o artista e o outro, mesmo quando o artista empreenda uma identificação para superar essa cisão. Sob a incumbência de proteção, essa posição pode reiterar a hierarquizaçáo das diferentes formas de vida e subjetividades.

Habita-se aí um paradoxo, pois, na medida em que essas açóes são categorizadas como arte, validadas por suas instituiçóes, elas correm o risco de serem capturadas e perderem sua potência disruptiva. Os artistas buscam assim, incessantemente, um lugar insurgente.

O insurgente é alguém que pensa e propóe viver fora. Mas, como o fora não existe em um mundo totalmente mapeado, esse fora deverá ser inventado. Para isso, muitos artistas insurgentes saem à procura de espaços, buracos, fendas no mapa urbano para experimentar novos possíveis. Quando descobertos, esses insurgentes são expostos à penalização (CARMINDA, 2011, p. 434).

Podemos traçar uma aproximação desta insurgência a situaçôes vividas concretamente por pessoas em processos de ruptura ligados a questóes sociais ou de saúde, as quais encontramos nos espaços comuns da cidade e também nos serviços de assistência, proteção social e de cuidado. Esses sujeitos vivem cotidianamente, por escolha ou não, espaços fora da vida normatizada. Mas o que se passa quando os artistas encontram insurgentes em seus contextos?

\section{Práticas em Composição}

Essas questôes atravessam o cotidiano vivido nas práticas que habitam a interface da saúde e da cultura. De um lado, encontram-se as práticas em terapia ocupacional, que tendem a sair de seus espaços tradicionais de atuação; de outro lado, os projetos artísticos que saem de seus domínios. Ambos os movimentos de escapar aos limites do que está instituído e assimilado na experiência cultural não garantem, por si só, uma nova reconfiguração e distribuição das linhas de forças que compóem os processos de subjetivação no contemporâneo. Mas, ao se movimentarem, podem criar oportunidades para a produção de novos acontecimentos, novos encontros.

Experimentações criadoras de sujeitos que são estrangeiros ao mundo das artes ganham uma outra dimensão e outro valor. No encontro com a diversidade de formas de existência e as formas expressivas as mais inusitadas, artistas buscam uma ruptura da linguagem artística e do sistema da arte para que se instaure a expressão (GULLAR, 1982).

Poderíamos dizer que se busca resgatar a eficácia da obra de arte, que diz respeito à sua potência para engendrar um devir, uma posterioridade, para instaurar novas esferas de possibilidades, novos campos de visibilidade e gerar seus próprios sujeitos. Entre a busca de ruptura da linguagem e o esforço por inserir na linguagem expressóes singulares, solitárias e, até então, sem sentido, o fazer artístico e o fazer terapêutico se encontram. Se a arte passa a poder comportar esse tipo de experiência-limite e, assim, "preparar, para além da cultura, uma relação com aquilo que a cultura rejeita" (BLANCHOT apud PELBART, 2000, p. 56), isso terá também profundas consequências para a clínica (LIMA, 2006, p. 325)

Neste contato dos artistas e das experiências criadoras com sujeitos estrangeiros ao mundo da arte, torna-se necessário resistir a esse desejo salvacionista da inclusão social, ao uso da arte e de qualquer 
outro fazer enquanto ferramenta para tal. E, nesse sentido, é necessário atravessar crises e desconfiar das próprias vontades de poder, já que, segundo a autora, trata-se de um

[...] ponto duro, essa inclusão salvacionista toma, muitas vezes de forma obstinada e fundamental, o funcionamento social hegemônico e central como sendo aquele ao qual deve-se fazer acessar todos os que gravitam a sua margem ou os que não estão a ele aderidos ou filiados, e por que não dizer, submetidos. Desprezada a oportunidade de se tomar a própria gravitação, ou não-adesão, ou desfiliação também como motivação para uma crítica, no sentido daquilo que coloca em crise a própria ordem social. Crise nos encontros, a desterritorialização da figura do técnico de saúde, educador e/ou assistente social provoca vertigem das posiçóes de ajuda e de saber, e portanto de poder (INFORSATO, 2010, p. 71).

Essas inquietações nos provocam a perguntar como desenvolver, no trabalho com pessoas enquadradas nessas populações, modos de intervenção que operem a partir da potência de sua posição, dessa recusa, dessas formas singulares. São pessoas que se encontram nos limites das curvas normativas e, assim, denunciam a complexidade dos processos de subjetivação que as produzem enquanto categorias, enquanto formas de nomear modos de ser, agir e pensar. Por múltiplas razões, desviam, não agem a partir do esperado e, no estranhamento que provocam, podem gerar diferenciaçôes. Insistem, talvez, com dissensos, potentes para a reconfiguração de certas posiçôes, como afirma Jacques Rancière:

Dissenso quer dizer uma organização do sensível no qual não há realidade oculta sob as aparências, nem regime único de apresentação e interpretaçáo do dado que imponha a todos sua evidência. É que toda situação é passível de ser fendida no interior, reconfigurada sob outro regime de percepção e significação. Reconfigurar a paisagem do perceptível e do pensável é modificar o território do possível e a distribuição de capacidades e incapacidades. O dissenso póe em jogo, ao mesmo tempo, a evidência do que é percebido, pensável e factível e a divisão daqueles que são capazes de perceber, pensar e modificar as coordenadas do mundo comum (RANCIĖRE, 2012, p. 48-49).

Tais problematizaçóes apontam tanto as capturas do poder pelos modos de produçáo capitalísticos quanto suas potências micropolíticas, com ênfase nos modos de dispor que podem gerar processos de subjetivação singulares, resistindo a uma forma homogeneizante da produção de subjetividade (ROLNIK; GUATTARI, 1989).

A análise dos mecanismos de poder náo tende a mostrar que o poder é ao mesmo tempo anônimo e sempre vencedor. Trata-se ao contrário de demarcar as posiçóes e os modos de ação de cada um, as possibilidades de resistência e de contra-ataque de uns e de outros (FOUCAULT, 1995, p. 12).

Ao pensarmos numa intervenção que atue no nível dos dispositivos, seria necessário jogar com os elementos constituintes dessa trama, embaralhando enunciados, campos de intervenção, domínios do saber, nominaçôes de práticas etc. Como instaurar espaços de encontro onde seja possível a criação de novos lugares, ou seja, a produção de subjetividades a partir da diferença? No contexto atual, essas diferenças são atribuídas a condiçôes pessoais e tratadas no interior dos serviços de saúde, de reabilitação, de assistência social etc. Em geral, espaços de pertencimento e participação social se reduzem à esfera do trabalho e do consumo. Mesmo locais destinados à convivência, como equipamentos e centros culturais, exigem, para que se permaneça neles, adaptaçóes a formas específicas de comportamento, não tolerando facilmente as marcas de uma diferença. Assim, pessoas que não respondem a essas adaptaçóes acabam não chegando a esses espaços. Os que chegam têm dificuldades para sustentar sua participação, pois há uma exigência de habilidades e recursos, a priori, que essas pessoas não possuem. Há pouca abertura para outras formas de lidar com o tempo, com os materiais, com os modos de se colocar, relacionar e produzir. Como considerar a potência dessas formas de vida, validando-as como possíveis, mas também reconhecendo seus graus de precariedade?

\section{Para Finalizar}

As experiências, os estudos e as reflexóes realizadas a partir dos analisadores acima discutidos mostram que são necessárias diferentes estratégias para promover processos de participação e singularização. Nesses processos, pode ser interessante a incorporação de estratégias clínicas que possam, além de facilitar essa participação, tensionar normas e procedimentos instituídos nos espaços de cultura e no próprio território da cidade, sustentando o volume dessa voz estrangeira onde ela, em geral, seria filtrada, abafada ou eliminada, o que pode propiciar sua ressonância. 
A presença de estratégias clínicas não garante a escuta dessa polifonia de vozes, pois o instituído resiste a estes embaralhamentos - que a própria presença dessas populaçôes já causa. Percebe-se, inclusive, que os espaços, na busca de apaziguar o incômodo que esses estranhamentos geram, criam dispositivos "de inclusáo", com projetos exclusivos para as diferentes populaçóes, que acabam por reiterar sua segregação.

Essa dinâmica denota o aspecto funcional dos espaços de convívio que, de forma disciplinar, delimitam categorias de encontros humanos. Os pontos de enunciação das diferentes práticas produzem efeitos no modo como nos dispomos nos ambientes, baseadas em contratos que estabelecem posiçôes. Por exemplo, espaços denominados como terapêuticos, educativos ou artísticos prometem determinadas experiências, mas não garantem seus efeitos. Pode ser que se vivam experiências estéticas na terapia, terapêuticas na aula de filosofia e educativas ao ver um espetáculo artístico. Nestes campos disciplinares e na vida no território, há diversos elementos dissonantes, que, muitas vezes, parecem ser ignorados da esfera de percepção que o discurso de uma disciplina circunscreve.

Dentro desse contexto, como criar ambientes de convivência que prescindam da redução a uma identidade ou função para sua participação? Espaços de circulação e produção onde insurgências resistam? É necessário repensar os contextos a partir de seus heterogêneos, de populaçóes heterogêneas. Heterogêneas não apenas na presença de pessoas sob diferentes categorizaçôes, mas na escuta ao heterogêneo que se manifesta nesses encontros, buscando captar singularidades para além de representaçóes dos diagnósticos sociais e de saúde.

Torna-se importante, por fim, refletir sobre a postura ética de habitar a posição de propositor de experiências em algum contexto das atividades humanas. Mais do que definir campos de intervenção específicos, disponibilizar-se para as sutilezas e a diferença, tecendo estratégias singulares de sentido compartilhado. Habitar interfaces em vez de estabelecer novos territórios.

Tudo aquilo que é tradução, transformação, passagem, é da ordem da interface. Pode ser um objeto simples como uma porta, mas também um agenciamento heterogêneo (um aeroporto, uma cidade), o momento de um processo, um fragmento de atividade humana. Estas entidades pertencem, sem dúvida, a reinos ou estratos ontológicos distintos, mas de um ponto de vista pragmático todas são condutores deformantes em um coletivo heterogêneo, cosmopolita. Os mais diversos agenciamentos compostos podem interfacear, ou seja, articular, transportar, difratar, interpretar, desviar, transpor, traduzir, trair, amortecer, amplificar, filtrar, inscrever, conservar, conduzir, transmitir ou parasitar (LÉVY, 1993, p. 114).

Ao habitar interfaces, soma-se à multiplicidade em vez de reduzir a híbridos. Náo se trata de intervençôes delimitadas num modelo de clínica ou de inclusão social através da arte ou da cultura. Em práticas culturais envolvendo populaçóes em situaçóes de vulnerabilidade, quanto mais a arte mantém sua autonomia dentro desse contexto, mais parece produzir processos de emancipação, em contraposição a uma ideia de inclusão social. A questấo da participaçáo social, dessa maneira, desloca-se do âmbito do sujeito, da inclusão de uma pessoa, para o âmbito dos dispositivos, de processos de emancipação que envolvem pessoas, mas também elementos heterogêneos: práticas discursivas e não discursivas, instituiçôes, localizaçóes de práticas, formas de relaçáo social, a retomada do espaço público etc.

A possibilidade de estabelecer outros tipos de contrato - ser um aluno de um curso, um participante de uma oficina ou um fotógrafo, por exemplo, e não apenas uma pessoa com diagnóstico psiquiátrico, usuária de um serviço de assistência social ou em situação de rua - permite ao sujeito ocupar outros lugares sociais. Esta pessoa não se transforma em um artista, mas descobre a possibilidade de transitar e inventar outros lugares no mundo. Uma espécie de travestimento, diferente da ideia de transformação ou de conversão. Essa possibilidade de travestir-se em diferentes papéis abre brechas no estabelecimento de outros tipos de contrato social, ampliando a realização de trocas a partir de novas posiçóes e, consequentemente, a autonomia. Dessa maneira, afirma-se a potência de produção e criação a partir da própria singularidade, que, ao ser reconhecida na trama da cultura, gera efeitos políticos.

Podemos problematizar a ideia de inclusão social a partir do conceito de emancipaçáo, proposto por Jacques Rancière. Em $O$ espectador emancipado (2012), o autor trabalha noçôes de emancipaçáo a partir de reflexóes sobre o lugar do espectador nas relaçóes entre arte e política. Para o autor, o efeito político da arte náo teria exclusivamente a ver com um intuito de promover transformaçóes sociais ou comunicar uma mensagem ideológica. Talvez esse efeito seja promovido pelo lugar transversal que instaura no espaço cotidiano, atravessando e sendo atravessado pelas linhas de poder, podendo propiciar processos de emancipação. Para ele, "uma comunidade 
emancipada é uma comunidade de narradores e tradutores" (RANCIÈRE, 2012, p. 21). Avessa à ideia de uma adaptação inclusiva, a emancipação tem a ver com a possibilidade de deslocar posiçôes, num poder de associar e dissociar:

A emancipação intelectual é a comprovação da igualdade das inteligências. Esta não significa igual valor de todas as manifestaçôes da inteligência, mas igualdade em si da inteligência em todas as suas manifestaçóes. [...] É o poder que cada um tem de traduzir à sua maneira o que percebe, de relacionar isso com sua aventura intelectual singular que o torna semelhante a qualquer outro, à medida que essa aventura não se assemelha a nenhuma outra. Esse poder comum de igualdade das inteligências liga indivíduos, faz que eles intercambiem suas aventuras intelectuais, à medida que os mantém separados uns dos outros, igualmente capazes de utilizar o poder de todos para traçar seu caminho próprio [...] É nesse poder de associar e dissociar que reside a emancipação do espectador, ou seja, a emancipação de cada um de nós como espectador. Ser espectador não é condição passiva que deveríamos converter em atividade. É nossa situação normal. Aprendemos e ensinamos, agimos e conhecemos também como espectadores que relacionam a todo instante o que veem ao que viram e disseram, fizeram ou sonharam. Não há forma privilegiada como não há ponto de partida privilegiado. Há sempre pontos de partida, cruzamentos e nós que nos permitem aprender algo novo caso recusemos, em primeiro lugar, a distância radical; em segundo, a distribuição dos papéis; em terceiro, as fronteiras entre os territórios. Não temos de transformar os espectadores em atores e os ignorantes em intelectuais. Temos de reconhecer o saber em ação no ignorante e a atividade própria ao espectador. Todo espectador é já ator de sua história; todo ator, todo homem de ação, espectador da mesma história (RANCIÈRE, 2012, p. 20-21).

Este caminho exige resistir ao sossego de delimitar um território murado e convida a que se habite uma vida nômade. Como sustentar desse tipo de experiência de interface? $\mathrm{O}$ fato de serem ainda pouco instituídas gera condiçôes de potência, mas também de grande precariedade. Para existirem, esses espaços desafiam normas e organizaçóes do cotidiano nos modos capitalísticos de vida: quem paga o custo para manutenção desses agenciamentos? Que lugares - espaços físicos - na cidade podem acolher esses encontros? Como criar espaços de convívio, abertos a qualquer um, onde se produzam imagens de modos de vida diversos a partir de fazeres coletivos? Como reunir populaçóes heterogêneas? Como redistribuir capacidades, saberes, poderes?

É nessa trama que o terapeuta ocupacional adentra quando atua nesses campos, podendo exercer diferentes funçóes em cada contexto. Às vezes, é preciso navegar pela própria experimentação artística, assumir certa autoria na condução das proposiçóes, posição esta diferente da ocupada na intervenção clínica. $\mathrm{Na}$ esfera clínica, é preciso agir com uma escuta delicadamente sensível à alteridade, gesto que parece constituir açôes de certas práticas artísticas, como as do cineasta que, para dar a ver linhas subjetivas, precisa calar sua direção. Mas é preciso pontuar algumas diferenças. Os projetos de artistas que trabalham a partir de processos colaborativos deixam claro que os mesmos assumem a autoria dos trabalhos e garantem que esses projetos se realizem. O que será que os mobiliza a produzir? O que mobiliza um terapeuta ocupacional a produzir? O que mobiliza um participante desses projetos a produzir? Objetivos diferentes conduzem processos, mas eles podem coexistir.

Os projetos construídos na interface saúde e cultura geram experiências que instauram possibilidades de se produzir numa diversidade de composiçôes. Além de colaboradores, os que participam tornam-se realizadores e, para esse processo acontecer, funções de agenciamento, manejo, articulação e organização dos ambientes são necessárias. A formação em Terapia Ocupacional, somada à prática da sensibilidade estética e à inserção em contextos socioculturais, tem se mostrado eficaz para o desenvolvimento dessas funçóes.

Dessa maneira, outras habilidades passam a compor os fazeres de um terapeuta ocupacional que atua no campo da cultura. Destaca-se a importância da formação em gestão e produção cultural para que experiências como estas ganhem existência a partir da inserção no sistema de cultura. Aprender a formatar projetos inserindo-os em editais de fomento cultural tem sido habilidades cruciais para propiciar a existência e a continuidade de projetos transversais e intersetoriais, incluindo, em sua formataçáo, singularidades advindas da sensibilidade que a formação e a prática em terapia ocupacional favorecem.

Mas, neste contexto, é necessário também desenvolver constantemente uma postura crítica nessa inserção, pois se corre o risco de institucionalizar práticas, podendo colocá-las a serviço de uma máquina de produzir cultura para manutenção e 
reprodução de regimes de poder. É preciso, assim, balbuciar diferentes línguas, permanecer estrangeiro na ocupação de territórios comuns. Mudar assim, as coordenadas do dizível, do pensável e do factível, como nos aponta Rancière (2012).

\section{Referências}

ALMEIDA, E. A. A. Cultura é regra, arte é exceção. In: ALMEIDA, E. A. A. Arte faz parte. [S.l.]: [s.n.], 2011. Blog. Disponível em: <http://www.artefazparte. com/2011/06/cultura-e-regra-arte-e-excecao.html>. Acesso em: 20 abr. 2016.

BRASIL. Câmara dos Deputados. Redação Final Projeto de Lei no 757-F de 2011. Institui a Política Nacional de Cultura Viva e dá outras providências. Diário Oficial do Estado do Rio de Janeiro, Rio de Janeiro, 10 out. 2011. Disponível em: <http://www.camara.gov.br/ proposicoesWeb/prop_mostrarintegra;jsessionid $=52 \mathrm{FC}$ DAEF053C4FBB19D8C6253CDE1CA6.proposic oes Web2 ? codteor $=1264479 \&$ filename $=$ Tramitacao -PL+757/2011>. Acesso em: 9 jul. 2014.

CARMINDA, A. Arte, biopolítica e resistência. Revista Brasileira de Estudos da Presença, Porto Alegre, v. 1, n. 2, p. 426-442, 2011.

CASTRO, E. D.; SILVA, D. M. Atos e fatos de cultura: território das práticas, interdisciplinaridade e as açōes na interface da arte e promoção da saúde. Revista de Terapia Ocupacional da USP, São Paulo, v. 18, n. 4, p. 1-10, 2007.

CENTRO DE CONVIVÊNCIA É DE LEI. [S.I.]: [s.n.], 2015. Disponível em: <www.edelei.org>. Acesso em: 24 out. 2015.

CLÍNICA DE PROJETOS. São Paulo, 2015. Disponível em: <www.projetosterapeuticos.com.br $>$. Acesso em: 24 out. 2015.

FAVARETTO, C. Arte contemporânea: obra, gesto e acontecimento. In: FAVARETTO, C.; MORENA, A. (Ed.). Filosofia, linguagem, arte. São Paulo: Educ, 1985. p. 93-98.

FOSTER, H. O artista enquanto etnógrafo. In: FOSTER, $H$. The return of the real: the avant-garde at the end of the century. London: The MIT Press, 1996. p. 175-207.

FOUCAULT, M. [1976]. História da Sexualidade I: a vontade de saber. Rio de Janeiro: Ediçóes Graal, 1997.

FOUCAULT, M. [1979]. Microfisica do poder. Rio de Janeiro: Ediçōes Graal, 1995.

GALARD, J. A beleza exorbitante: reflexôes sobre o abuso Estético. São Paulo: Editora Fap-Unifesp, 2012.

GUIZARDI, F.; CAVALCANTI, F. Por um mundo democrático produzido democraticamente (ou: o desafio da produção do comum). Lugar Comum: Estudos de
Mídia, Cultura e Democracia, Rio de Janeiro, n. 27, p. 103-123, 2009.

GULLAR, F. Sobre arte. Rio de Janeiro: Avenir, 1982.

HALL, S. A centralidade da cultura: notas sobre as revoluçōes culturais do nosso tempo. Educação \& Realidade, Porto Alegre, v. 22, n. 2, p. 15-46, 1997.

INFORSATO, E. A. Adaptação e simpatia: trajetórias críticas na clínica. Interface: Comunicação, Saúde, Educação, Botucatu, v. 15, n. 38, p. 929-936, 2011.

INFORSATO, E. A. Desdobramento: constelaçôes clínicas e políticas do comum. 2010. 217 f. Tese (Doutorado em Filosofia e Educaçáo) - Universidade de São Paulo, São Paulo, 2010.

LEMOS, F. C. S. História, cultura e subjetividade. Revista do Departamento de Psicologia, Rio de Janeiro, v. 19, n. 1, p. 61-68, 2007.

LÉVY, P. As tecnologias da inteligência: o futuro do pensamento na Era da Informática. Rio de Janeiro: Ed. 34, 1993.

LIMA, D. R. As teias de uma rede: uma análise do programa cultura viva. 2013. 214 f. Dissertação (Mestrado em História, Política e Bens Culturais) - Fundação Getúlio Vargas, Rio de Janeiro, 2013.

LIMA, E. M. F. A. Desejando a diferença: consideraçōes acerca das relaçóes entre os terapeutas ocupacionais e as populaçōes tradicionalmente atendidas por estes profissionais. Revista de Terapia Ocupacional da USP, São Paulo, v. 14, n. 2, p. 64-71, 2003.

LIMA, E. M. F. A. et al. Ação e criação na interface das artes e da saúde. Revista de Terapia Ocupacional da USP, Sáo Paulo, v. 20, n. 3, p. 143-148, 2009.

LIMA, E. M. F. A. Por uma arte menor: ressonâncias entre arte, clínica e loucura na contemporaneidade. Interface: Comunicação, Saúde, Educação, Botucatu, v. 10, n. 20, p. 317-329, 2006.

PASSOS, E.; KASTRUP, V.; ESCÓSSIA, L. Pistas para o método da cartografia: pesquisa-intervenção e produção de subjetividade. Porto Alegre: Sulina, 2010.

PÉLBART, P. P. Poder sobre a vida, potência da vida. $L u-$ gar Comum: Estudos de Mídia, Cultura e Democracia, Rio de Janeiro, n. 17, p. 33-43, 2008.

PONTO de Culura é de Lei. [S.I.]: [s.n.], 2015. Disponível em: <www.youtube.com/pontodeculturaedelei> Acesso em: 24 out. 2015.

RANCIÈRE, J. O espectador emancipado. São Paulo: WMF Martins Fontes, 2012.

ROLNIK, S.; GUATTARI, F. Micropolitica: cartografias do desejo. Petrópolis: Vozes, 1989.

TURINO, C. Ponto cultura: o Brasil de baixo para cima. São Paulo: Anita Garibaldi, 2010. 
VALENT, I. U. Fazer imagens, inventar lugares: experimentações fotográficas e audiovisuais em práticas artísticas na interface Cultura e Saúde. 2014. 153 f. Dissertação (Mestrado em Estética e História da Arte) Universidade de São Paulo, São Paulo, 2014.
VIMEO. N.A.V.E. [S.1.]: [s.n.], 2015a. Disponível em: <www.vimeo.com/nave>. Acesso em: 24 out. 2015.

VIMEO. Projeto encontrar-te. [S.1.]: [s.n.], 2015b. Disponível em: <www.vimeo.com/encontrarte>. Acesso em: 24 out. 2015 .

\section{Contribuição dos Autores}

Isabela Umbuzeiro Valent realizou a sistematização e seleção dos materiais que compuseram a redação do artigo e a sua revisão final. Eliane Dias de Castro orientou a pesquisa e a seleçáo do material para a escrita do artigo, bem como co-redigiu o texto e realizou sua revisão final. Todos os autores aprovaram a versão final do texto.

\section{Fonte de Financiamento}

\section{CAPES.}

\section{Notas}

${ }^{1}$ Este artigo apresenta algumas das reflexôes da pesquisa de mestrado "Fazer imagens, inventar lugares. Experimentaçôes fotográficas e audiovisuais em práticas artísticas na interface Cultura e Saúde”, 2014, desenvolvida no Programa de Pós-graduação em Estética e História da Arte da Universidade de São Paulo, de autoria de Isabela Umbuzeiro Valent, com orientação de Eliane Dias de Castro.

${ }^{2}$ Núcleo Audiovisual Experimental (NAVE): oficina de vídeo documentário ligada a um programa de saúde mental do Instituto Projetos Terapêuticos (CLÍNICA..., 2015; VIMEO, 2015a).

${ }^{3}$ Encontrar-te: projeto experimental e autônomo, desenvolvido por terapeutas ocupacionais com formaçốes em artes, de circulação em grupo na cidade de São Paulo, envolvendo pessoas com questōes ligadas a sofrimentos psíquicos e deficiências intelectuais (VIMEO, 2015b).

${ }^{4}$ Ponto de Cultura É de Lei: açốes de um ponto de cultura vinculado ao Centro de Convivência É de Lei (2015), uma organização da sociedade civil que desenvolve estratégias de redução de riscos e danos socias e à saúde associados ao uso de drogas. Visualizar vídeos em www.youtube.com/pontodeculturaedelei (PONTO..., 2015).

${ }^{5}$ Atualmente, o Programa segue em funcionamento pela atual Secretaria de Cidadania e Diversidade Cultural (SCDC) do MinC e acaba de tornar-se lei: no dia 1. ${ }^{\circ}$ de julho de 2014, foi aprovado pela Câmera dos Deputados o Projeto de Lei n. ${ }^{0}$ 757-F, que institui a Política Nacional de Cultura Viva (BRASIL, 2014).

${ }^{6}$ A obra foi exibida no Brasil na 29a Bienal de São Paulo, em 2011. Je Vous Salue Sarajevo. Direção: Jean-Luc Godard, 1993.

7 Transcrição da narração retirada do artigo "Cultura é regra, arte é exceção" publicado no blog artefazparte.com, de autoria de Eduardo Almeida (ALMEIDA, 2011). 